\title{
Impact of moisture content on instant catapult steam explosion pretreatment of sweet potato vine
}

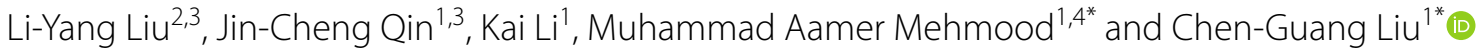

\begin{abstract}
Background: Lignocellulose originating from renewable and sustainable biomass is a promising alternative resource to produce biofuel. However, the complex component, especially high moisture content, leads to a higher cost of transportation and processing. The instant catapult steam explosion (ICSE) pretreatment can exploit the intracellular water of lignocellulosic materials and convert into vapors leading towards the breakdown of the feedstock during the explosion process. However, it is necessary to study the impact of moisture content on the pretreatment.

Results: The sugar yield of wet feedstock after ICSE pretreatment reached $88.05 \%$, which was higher when compared to dried and untreated biomass. The utilization of wet feedstock decreased the production of inhibitor and improved the carbohydrate content in ICSE-treated biomass. There occurred a shrinkage of feedstock after drying process and the mechanical breakage upon ICSE pretreatment. Moreover, not all water was converted into vapor to cause breakage in the lignocellulose.

Conclusion: ICSE has shown to be preferably suitable to pretreat wet sweet potato vine with high moisture content, either fresh or soaked biomass that has been dried before. By using these materials, it would have a higher sugar yield and lower inhibitor production after pretreatment. Based on these advantaged aspects of ICSE platform, two potential strategies are proposed to improve the economic and environmental impacts of pretreatment.
\end{abstract}

Keywords: Pretreatment, Moisture content, Instant catapult steam explosion, Sweet potato vine, Enzymatic hydrolysis

\section{Background}

Nowadays, lignocellulosic biomass offers a promising alternative to produce biofuel owing to its abundance, renewability, and sustainability. However, the recalcitrant nature of biomass requires additional pretreatment steps to make it susceptible to cellulolytic enzymes (Mosier et al. 2005). Generally, pretreatment efficiency depends on low moisture content and small particle size of the biomass which also would reduce the cost of transportation (Vidal et al. 2011). However, traditional drying

\footnotetext{
*Correspondence: draamer@gcuf.edu.pk; cc.liu@sjtu.edu.cn ${ }^{1}$ State Key Laboratory of Microbial Metabolism, School of Life Sciences and Biotechnology, Shanghai Jiao Tong University, Shanghai 200240, China ${ }^{4}$ Department of Bioinformatics and Biotechnology, Government College University Faisalabad, Faisalabad 38000, Pakistan

Full list of author information is available at the end of the article
}

process is an energy intensive process and the solar irradiance is limited in countries like China as compared to South Asia or Africa; thus, the air-drying process will occupy vast agriculture area preventing in-time crop rotation. So, to keep the crop rotation framework intact, most of lignocellulosic biomass is burnt on the field during harvesting seasons in northern China, causing atmosphere pollution and public health hazards (Tan et al. 2010; Qu et al. 2012). Alternatively, this low-cost biomass may be subjected to efficient pretreatment which do not involve drying step.

Fortunately, steam explosion pretreatment in principle requires higher moisture content in lignocellulose biomass, which may improve the efficiency of pretreatment. The biomass is usually treated under high pressure for several seconds to minutes to prompt the hydrolysis of 
hemicellulose content and then release the pressure with a short time to break the microstructure of lignocellulose (Galbe and Zacchi 2012). Previous researchers adopted steam explosion to pretreat wet corn stalk and found that higher initial moisture content would improve enzymatic hydrolysis of lignocellulose and reduce $20 \%$ of steam consumption, because water in feedstock presented a buffering effect on reaction during steam explosion process (Sui and Chen 2015).

However, the traditional steam explosion instrument will produce abundant of inhibitors such as acetic acid, furfural, coumaric acid, and 5-hydroxymethylfurfural (5-HMF). Moreover, the longer pretreatment time will consume more energy (Cullis et al. 2004). To offset these drawbacks, instant Catapult Steam Explosion (ICSE) was invented. The short de-pressure time $(0.0825 \mathrm{~s})$ and pretreatment duration (1-5 min) provide ICSE huge mechanical force to destruct the biomass structure and less energy consumption with simple operation than traditional steam explosion (Gong et al. 2012). Previously, it has been demonstrated that ICSE can improve the enzymatic degradability of lignocellulose with few inhibitors and less energy consumption (Liu et al. 2014a). ICSE also has positive impacts on the efficiency of subsequent chemical pretreatments involved with organic solvent, acid, and alkali (Liu et al. 2014b).

Sweet potato (Ipomoea batatas) belongs to the family Convolvulaceae, containing abundant starch in the root. So far, China being the largest producer of sweet potato in the world has planted over 6.2 million hectares, and produces over 71 million tons of sweet potatoes, which accounts for the $67 \%$ of the global production (Fao 2016). The high sugar content and easily cultivated in saline and alkali land of sweet potato allow it to be used as an excellent resource to produce biofuels (Xia et al. 2013). Although significant advancements have been made on the conversion of sweet potato yet the progress made is not up to the desired levels. Many sweet potato vines including leaves, stems, and petiole are disposed in the farming field or used as lowvalue product like animal feed (Tian et al. 2009). Comparing with other lignocellulose resources such as corn stover and rice stalk, sweet potato vine contains higher moisture content and extractives (Jibril et al. 1999). These characters may be helpful to study the effects of lignocellulosic moisture content on ICSE pretreatment.

In present study, sweet potato vines were used to study the effects of moisture content on ICSE pretreatment by investigating the composition, inhibitors production, sugar yield, and thermal stability, for different feedstock including fresh feedstock, naturally dried feedstock, manually dried feedstock, and soaked dried feedstock. It was studied as a simple and practical method to obtain wet lignocellulose for both industry and lab.

\section{Methods}

Biomass collection and management

Fresh sweet potato vines were collected from a field near the city of Dalian in China during the summer, which contained $16.8 \%$ cellulose, $9.6 \%$ hemicellulose, $42.89 \%$ lignin and ash, $17.6 \%$ protein, and $1.5 \%$ fat after dried. Collected materials were cut into 1 - to $2-\mathrm{cm}$ fragments by scissors, and stored at $-20{ }^{\circ} \mathrm{C}$ for further use.

Fresh feedstocks (FF) were treated in different ways to obtain materials with different moisture contents. FF was dried by natural environment under the sun for 1 week (NDF), which was close to the natural condition before collecting the samples from the field. FF was also dried at $65{ }^{\circ} \mathrm{C}$ to the constant weight. This manually dried feedstock (MDF) is widely accepted for the pretreatment.

Samples with coordinating water were also prepared by soaking $20 \mathrm{~g}$ MDF into $200 \mathrm{~mL}$ of tap water at room temperature at a short time for $2 \mathrm{~h}$ (SF-2), medium time (30 h, SF-30), and a long time (60 h, SF-60). To stop the soaking processing and stabilize the moisture content, the Buchner funnels with filter paper were used to separate the liquid and wet feedstock. Water on the surface of wet feedstock was cleaned by filter paper, following to put in the desiccator to stabilize their moisture content for $24 \mathrm{~h}$. All feedstocks were sealed and stored at $-20{ }^{\circ} \mathrm{C}$.

\section{Chemicals and enzymes}

Analytical grade glucose, xylose, furfural, 5-hydroxymethyl furfural (5-HMF), acetic acid, and coumaric acid were purchased from Sangon Biotech Crop. (Shanghai, China) and Solarbio Life Science Corp. (Beijing, China). Cellulase (GENENCOR accelerase 1500, cellulase enzyme activity: $105 \mathrm{FPU} / \mathrm{mL}$ ) was kindly donated by Dupoint Genicor Science Corp. (Shanghai, China).

\section{ICSE pretreatment}

$20 \mathrm{~g}$ of biomass including FF, NDF, MDF, SF-2, SF-30, and SF-60 were loaded directly into $400-\mathrm{mL}$ chamber of the ICSE equipment (QBS-80B Steam Explosion Test Bed, Henan Hebei, Zhengdao Corp.). Steam with pressure $(3.25 \mathrm{MPa})$ and temperature $\left(240{ }^{\circ} \mathrm{C}\right)$ was prepared in advance and sent into the chamber to make the pretreated pressure be stabilized at $2.8 \mathrm{MPa}$ for $90 \mathrm{~s}$ by controlling the quantity of flow. After this pretreatment, the ICSE-treated sweet potato vines were released from the chamber by depressurization in $0.0825 \mathrm{~s}$, causing treated material to explode into a stainless-steel cyclone. The slurry (treated material) was collected by scoop into the plastic bag, and then sealed and stored at $-20{ }^{\circ} \mathrm{C}$ for further compositional and enzymatic hydrolysis analysis (Liu et al. 2014a). 


\section{Moisture content analysis}

The moisture content $\left(C_{\mathrm{m}_{1}}\right)$ of materials before and after ICSE pretreatment was calculated via the equation

$$
C_{\mathrm{m}_{1}}=\left(X_{1}-X_{2}\right) / X_{1},
$$

where $X_{1}$ is the mass before oven drying and $X_{2}$ is the mass after drying in the $65{ }^{\circ} \mathrm{C}$ oven to get a constant weigh.

\section{Inhibitor and sugar analysis after ICSE pretreatment}

5 grams of each of the ICSE-treated materials were centrifuged in $1957 \times g$ for $10 \mathrm{~min}$. The supernatants were used for inhibitor and sugar concentration $\left(C_{\mathrm{i}}\right)$ analysis by high-performance liquid chromatography analysis. The solid components were dried at $65{ }^{\circ} \mathrm{C}$ to get a constant weight $\left(X_{3}\right)$. After the analysis of liquor solution, the inhibitor and sugar yield $(\mathrm{mg} / \mathrm{g})$ after ICSE pretreatment were calculated by the equation: inhibitor yield $=C_{\mathrm{i}} \times\left(5-X_{3}\right) / X_{3}$. All experiments were performed in triplicate and the results are presented as mean and standard derivation.

\section{Compositional analysis}

Untreated MDF and solid components of ICSE-pretreated samples were totally dried and finely ground to less than 40-mesh. $100 \mathrm{mg}$ of each sample was mixed with $1 \mathrm{~mL}$ of $72 \%(\mathrm{w} / \mathrm{v})$ sulfuric acid, and placed in the $50-\mathrm{mL}$ colorimetric tube. The tubes were incubated at $30{ }^{\circ} \mathrm{C}$ water bath for $1 \mathrm{~h}$ with stirring every $10 \mathrm{~min}$ to ensure the intensive mixing. After $1 \mathrm{~h}$, final concentration of acid was brought to $4 \%$ by adding $28 \mathrm{~mL}$ of deionized water, and was put in the autoclave at $121{ }^{\circ} \mathrm{C}$ for $1 \mathrm{~h}$. After that, all tubes were left to cool down to room temperature, and the treated samples were filtered by the Buchner funnel with Whatman No.1 filter paper. The supernatants of each tube were used to analyze the glucose, cellobiose, xylose, and arabinose, representing cellulose and hemicellulose, respectively. The solid components were thoroughly washed and dried until it reached a constant weight, representing lignin and ash content. All experiments were performed in triplicate and the results are presented as mean and standard deviations (Sluiter et al. 2012).

\section{Enzymatic hydrolysis}

Untreated and the solid fractions of ICSE-pretreated samples were accurately weighted $(300 \mathrm{mg})$ and placed in the $50-\mathrm{mL}$ colorimetric tubes, suspended in $30 \mathrm{~mL}$ buffer solution (acetic acid, $\mathrm{pH}$ 4.8) containing the enzyme at the ratio of $30 \mathrm{FPU} / \mathrm{g}$. The mixture was incubated at $50{ }^{\circ} \mathrm{C}$ for $48 \mathrm{~h}$ followed by a centrifugation. Supernatant was subjected to sugar content analysis, as described previously (Liu et al. 2014a, b). The sugar yield was calculated by Eq. (1) below:

$$
\begin{aligned}
\text { Sugar yield }(\%)= & \frac{[(\text { glucose } \times 0.9)+(\text { xylose } \times 0.8)]}{\text { carbohydrate in biomass }} \\
& \times 100 .
\end{aligned}
$$

Glucose and xylose were analyzed by the HPLC. All experiments were performed in triplicate, and results are presented as mean and standard deviations.

\section{High-performance liquid chromatography analysis}

The supernatant from ICSE-pretreated samples and enzymatic hydrolysis were filtered through $0.45-\mu \mathrm{m}$ filter and $20 \mu \mathrm{L}$ of each sample was loaded to the ion exclusion column $(300 \mathrm{~mm} \times 7.8 \mathrm{~mm}$, Bio-Rad, Hercules, Aminex HPX-87H) at $50{ }^{\circ} \mathrm{C}$ in HPLC system equipped with a refractive index detector and UV detector (Waters, MA, USA), for the quantitation of inhibitors and saccharides. Sulfuric acid $0.01 \mathrm{~mol} / \mathrm{L}$ was used as mobile phase at flow rate $0.5 \mathrm{~mL} / \mathrm{min}$ (Liu et al. 2014a).

\section{Scanning electron microscopy (SEM)}

The microscopic morphology changes in the untreated and ICSE-pretreated samples after dried by lyophilization were observed using SEM. Each of the samples was placed on the aluminum sample platform and scanned by environmental scanning electron microscopy (Quanta 450, FEI, USA20 kV), using $20 \mathrm{kV}$ as described previously (Liu et al. 2014a).

\section{Thermal gravimetric analysis (TGA)}

About $10 \mathrm{mg}$ of freeze-dried MDF, ICSE-treated FF, and ICSE-treated MDF were placed in the platinum crucibles for thermal degradation analyses using TGA Q500 (TA Corporation, USA). Samples were heated from 25 to $500{ }^{\circ} \mathrm{C}$ at a constant heating rate of $10{ }^{\circ} \mathrm{C} / \mathrm{min}$ under nitrogen atmosphere at the flow rate of $50 \mathrm{~mL} / \mathrm{min}$ (Carrier et al. 2011).

\section{Results and discussion}

The change of moisture content in different feedstock

Moisture content of any plant biomass is an important parameter for its subsequent usage as a feedstock for bioenergy. To evaluate the effect of moisture content on pretreatment and enzymatic hydrolysis, five forms of samples were prepared (Table 1). FF normally contains $80.50 \%$ to sustain the growth of plants. NDF shown to contain $63.57 \%$ moisture content which was obtained through exposure of harvested FF under the sun for 7 days. MDF was subjected to soaking to regain the moisture content. Interestingly, the moisture content of SF immediately came up to $62.93 \%$ through submerging 
Table 1 The moisture content and the compositional analyses of liquid phase after ICSE pretreatment

\begin{tabular}{|c|c|c|c|c|c|c|}
\hline Feedstocks & $\mathrm{FF}$ & NDF & MDF & SF-2 & SF-30 & SF-60 \\
\hline \multicolumn{7}{|c|}{ Moisture content (\%) } \\
\hline Untreated & 80.50 & 63.57 & 0.97 & 62.93 & 83.38 & 84.24 \\
\hline Pretreated & 96.95 & 96.04 & 93.30 & 95.62 & 97.90 & 97.29 \\
\hline \multicolumn{7}{|l|}{ Liquid contents } \\
\hline \multicolumn{7}{|l|}{ Pretreated $(\mathrm{mg} / \mathrm{g})$} \\
\hline Glucose & $0.7865(0.0649)$ & $0.3798(0.0123)$ & $0.2638(0.0279)$ & $0.0284(0.0091)$ & $0.0008(0.0012)$ & $0.0000(0.0000)$ \\
\hline Xylose & $0.8858(0.0577)$ & $0.5393(0.0292)$ & $0.4733(0.0320)$ & $0.0682(0.0137)$ & $0.0031(0.0020)$ & $0.0006(0.0000)$ \\
\hline Acetic acid & $0.0768(0.0049)$ & $0.0926(0.0007)$ & $0.1293(0.0019)$ & $0.0496(0.0015)$ & $0.0674(0.0517)$ & $0.0000(0.0000)$ \\
\hline Coumaric acid & $0.2405(0.0827)$ & $0.4769(0.0303)$ & $0.7838(0.0149)$ & $0.2797(0.0136)$ & $0.0659(0.1110)$ & $0.0241(0.0000)$ \\
\hline 5-HMF & $0.0702(0.0247)$ & $0.0492(0.0325)$ & $0.0418(0.0021)$ & $0.0231(0.0080)$ & $0.0059(0.0040)$ & $0.0041(0.0008)$ \\
\hline Furfural & $24.17(2.18)$ & $17.41(0.74)$ & $34.81(0.96)$ & $18.76(1.04)$ & $5.37(1.40)$ & $5.42(0.24)$ \\
\hline
\end{tabular}

Data were shown as "mean (standard deviation)"

MDF for $2 \mathrm{~h}$ and finally stabilized at around $84.24 \%$ at $60 \mathrm{~h}$. The moisture content of SF-60 was close to that of FF, which may be attributed to water absorption by favorable hydrophilic component and the sponge-like structure of lignocellulose (Dhakal et al. 2007). In addition, it is worth mentioning that, to achieve the same available biomass, the weight of MDF was one-fifth of $\mathrm{FF}$, so the drying process could significantly reduce the total weight of lignocellulose, which is very important for biomass transportation (Axelsson et al. 2012). Moreover, soaking is a convenient way to regain the water, if required, after the easy transportation of dried biomass to the biofuel industry.

ICSE-pretreated sample contained higher moisture content ranging from 93.30 to $97.90 \%$, which was caused by the abundant liquefied water condensed from the steam and stored in the pores of feedstock after the explosion (Table 1). Since the initial moisture content of feedstock also affects the final moisture content, it is obvious to get similar trends of moisture content after pretreatment. However, the ICSE pretreatment demonstrated its capability to smooth the difference of moisture content among all samples, which nullify the impact of drying on ICSE.

\section{Composition and inhibitors in pretreated feedstocks}

The pretreatment with high temperature that can contribute to enhance the available sugars upon hydrolysis is preferred in the bioconversion of biomass to biofuels. However, under high-temperature pretreatment, the lignocellulose will be partially degraded to inhibitors such as organic acid, furfural, 5-HMF, which drastically hinder the efficiency of enzymatic hydrolysis and fermentation process (Jönsson et al. 2013). The 5-HMF, furfural, and coumaric acid, respectively, represent the cellulose, hemicelluloses, and lignin, and reflect the compositional
Table 2 The compositional analysis of untreated MDF and the solid contents after ICSE pretreated

\begin{tabular}{lccc}
\hline & Cellulose/\% & Hemicellulose/\% & Lignin and ash/\% \\
\hline $\begin{array}{l}\text { Untreated } \\
\text { MDF }\end{array}$ & $16.83(1.86)$ & $9.60(1.20)$ & $42.88(0.67)$ \\
$\begin{array}{l}\text { Pretreated } \\
\text { FF }\end{array}$ & $40.25(1.62)$ & $10.27(0.13)$ & $22.39(0.52)$ \\
NDF & $41.10(2.18)$ & $10.92(0.90)$ & $19.66(2.91)$ \\
MDF & $41.96(4.66)$ & $8.23(1.40)$ & $24.76(1.86)$ \\
SF-2 & $42.28(1.75)$ & $10.95(1.96)$ & $23.88(4.41)$ \\
SF-30 & $48.69(1.35)$ & $15.04(0.92)$ & $20.40(1.85)$ \\
SF-60 & $48.38(0.31)$ & $15.95(0.86)$ & $21.28(2.77)$ \\
\hline
\end{tabular}

Data were shown as "mean (standard deviation)"

change of untreated and pretreated biomass (Vander et al. 2014).

Table 2 shows that ICSE improved the cellulose content from 16.83\% (untreated MDF) to 40.25-48.69\% (ICSE treated), accompanied with the reduction of "lignin" from 42.88\% (untreated MDF) to 19.66-24.76\% (ICSE treated) and the change of hemicelluloses content from 9.60\% (untreated MDF) to 8.23-15.95\% (ICSE treated). The "lignin" content in the solid phase was higher than that of references' data, since the protein, fats, and extractives may mix with lignin to impact the acid insoluble lignin and the acid soluble lignin (Jibril et al. 1999). In spite of considerable degradation of hemicelluloses under high temperature, the removal of abundant organic extractives and proteins helped hemicelluloses maintain the content percentage and even better (Zhan et al. 2013; Rocha et al. 2012). This may also explain the significant reduction of "lignin" content in feedstocks after ICSE pretreatment, since extractives, fats, or proteins in detected "lignin" might easily to be hydrolyzed within higher temperature 

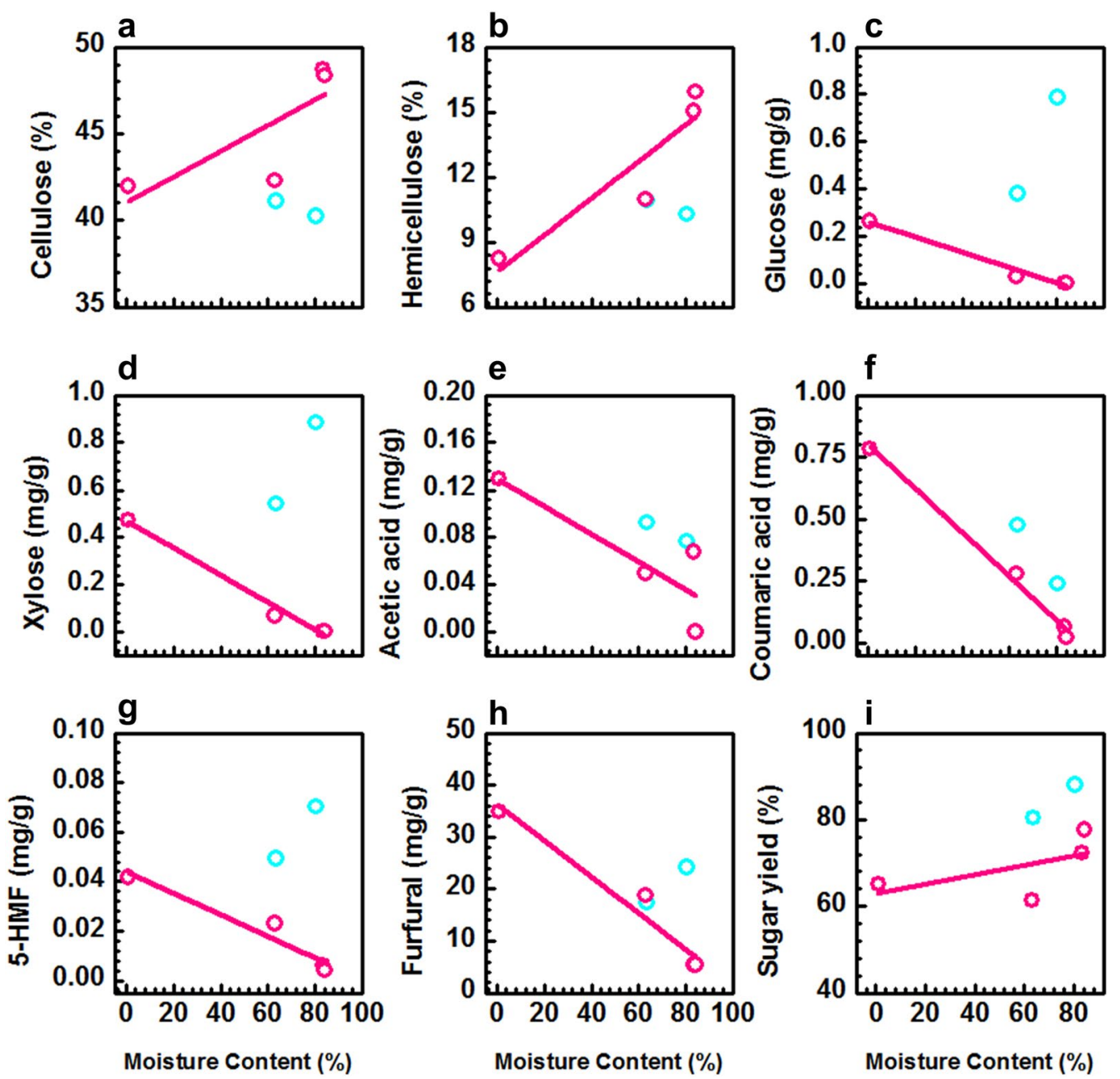

Fig. 1 Effects of moisture content on components, inhibitors, and sugar yield. Carbohydrates (a cellulose, $\mathbf{b}$ hemicellulose) in the solid fraction, sugar (c glucose, $\mathbf{d}$ xylose), and inhibitors (e acetic acid, $\mathbf{f}$ coumaric acid, G 5-HMF, $\mathbf{h}$ furfural) in the liquid fraction, and sugar yield (i) of ICSE-pretreated feedstocks after enzymatic hydrolysis. Cyan plots: FF and NDF; pink plots: MDF, SF-2, SF-30, SF-60

during ICSE pretreatment. Figure 1a, b shows the positive correlation for linear fitting between cellulose (hemicelluloses) and the moisture content in MDF, SF-2, SF-30, and SF-60 after ICSE pretreatment. Those four feedstocks marked in pink color share the oven-drying process in common. The oven-drying process with rapid dehydration of feedstock under higher temperature resulted in significant structure change from FF (Fig. 4). Therefore, it is worth noticing that two cyan scatters representing FF and NDF were non-compliance with the line correlation among those four feedstocks, since the plant's intracellular components would impact the yields of sugar and inhibitor at non-soaking conditions.

Figure 1c, $d$ illustrates a negative correlation between glucose (xylose) in the liquid phase and the moisture content. The $R^{2}$-value was more than 0.98 which strongly validates the reliability of linear relationships. Soaking will dissolve low molecule sugar from feedstock, so the feedstock after long-time soaking lost a plenty of soluble sugar. Though the portion of glucose and xylose was derived from the thermal degradation of cellulose and hemicelluloses, ICSE mainly acts as physical pretreatment and produces little monosaccharides. Therefore, soaking is the prior factor to reduce the glucose and xylose in liquid phase. Interestingly, FF contained mostly glucose and xylose, which were nutrients for sweet potato cell in the vine after harvesting. After 7 days drying, the glucose and xylose decreased due to continuous respiration by living cells in NDF.

The inevitable high-temperature process during ICSE pretreatment converts some lignocellulose to inhibitory by-products such as 5-HMF, furfural, acetic acid, and coumaric acid from hexose, pentose, and lignin, respectively (Table 1). The correlation of inhibitor and moisture 
content was consistent with the relation between sugar and moisture content (Fig. 1). Among these inhibitors, the coumaric acid and furfural produced from lignin and hemicelluloses, respectively, were higher than others, which reflected that ICSE process could more easily hydrolyze lignin and hemicelluloses than cellulose (Liu et al. 2014a). Since soaking is analogous to washing and can rinse monosaccharides and oligosaccharides out of the material surface (Frederick et al. 2014), longer soaking time diminished the surface residual sugars and subsequently decreased the accumulation of inhibitors during ICSE pretreatment (Table 1).

The pretreatment efficiency is not only determined by the moisture content of feedstock, but also by the method of feedstock handling. Therefore, the structure of feedstock should be analyzed for further understanding of this process.

\section{Thermal degradation analysis of untreated and ICSE-pretreated feedstocks}

Thermal stability of the biomass is analyzed by using TGA, a widely adopted technique to determine the thermal degradation of plant biomass (Carrier et al. 2011; Sanchez-Silva et al. 2012). In general, the differential-TG (DTG) curves of lignocellulose biomass often show three main peaks: one reflects the evaporation of extractives or water at $100-200{ }^{\circ} \mathrm{C}$, the others stand for degradation of cellulose and lignin at $300-350$ and $300-500{ }^{\circ} \mathrm{C}$, respectively. The DTG curve usually exhibits shoulders in the temperature range of $200-300{ }^{\circ} \mathrm{C}$, corresponding to the hemicelluloses degradation. The relative intensities of each peak could be used to calculate the quantities of hemicelluloses, cellulose, and lignin present in the lignocellulose (Carrier et al. 2011).

Interestingly, the respective hemicelluloses shoulder of MDF's DTG curve almost disappeared after ICSE pretreatment and the height of its maximum peak increased $12.5 \%$

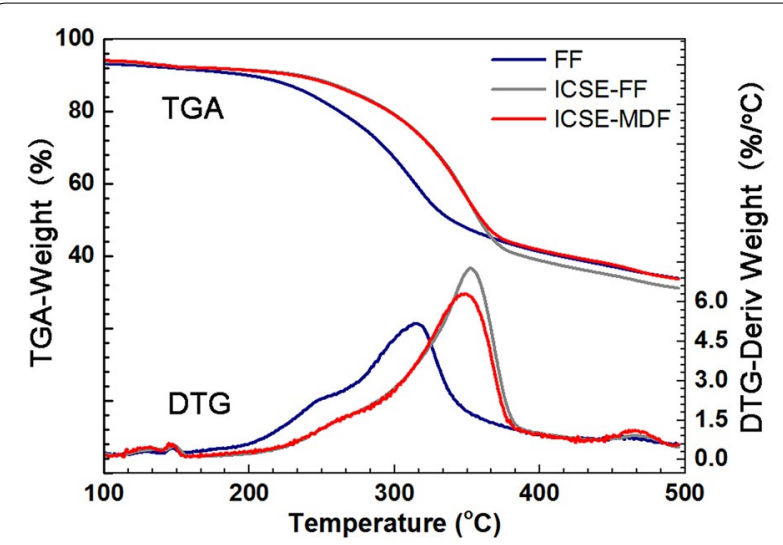

Fig. 2 TGA and DTG analysis of FF, ICSE-FF, and ICSE-MDF and moved to a higher temperature due to the degradation of hemicelluloses and the related lifting of cellulose (Fig. 2). Noticeably, it is highly consistent for the temperature and area of DTG curves' shoulder with a range from 200 to $350{ }^{\circ} \mathrm{C}$ between ICSE-FF and ICSE-MDF due to their minor variance of carbohydrate content, less than $0.66 \%$. This finding was further confirmed by the compositional analysis (Table 2). In summary, ICSE pretreatment degraded the hemicelluloses content and nullified the impact of drying process on the change of lignocellulosic composition when compared to wet feedstock.

\section{Impact of pretreatment on enzymatic hydrolysis}

The enzymatic hydrolysis is the key step to obtain the fermentable sugars from lignocellulosic biomass. Before pretreatment, handling operation enhanced the structural and compositional change of feedstock (Table 2 and Fig. 3), which can be confirmed by sugar yield after enzymatic hydrolysis. NDF and MDF owned better sugar yield than FF, and soaking duration further improved the sugar yield. The soaking process could wash away some chemical composition that might inhibit enzymolysis or lead to invalid enzymatic adsorption (Frederick et al. 2014). In addition, the hornification effects due to the drying process for MDF might lead the plant to have a lower accessibility to enzyme or chemical reagents, which might also inhibit the enzymatic hydrolysis (Fernandes et al. 2004).

A considerable pretreatment method should ensure that pretreated feedstocks are suitable for robust saccharification (Agbor et al. 2011). Figure 1 illustrates that ICSE pretreatment significantly enhanced the enzyme hydrolysis when compared to the untreated feedstocks. Especially, the sugar yield of ICSE-FF was shown a fourfold increment and reached to the maximum value $(88.05 \%)$ of all samples. At this condition, sugar concentration after enzymatic hydrolysis is about $5.18 \mathrm{~g} / \mathrm{L}$. Similar improvements were observed in NDF and soaked biomass. These

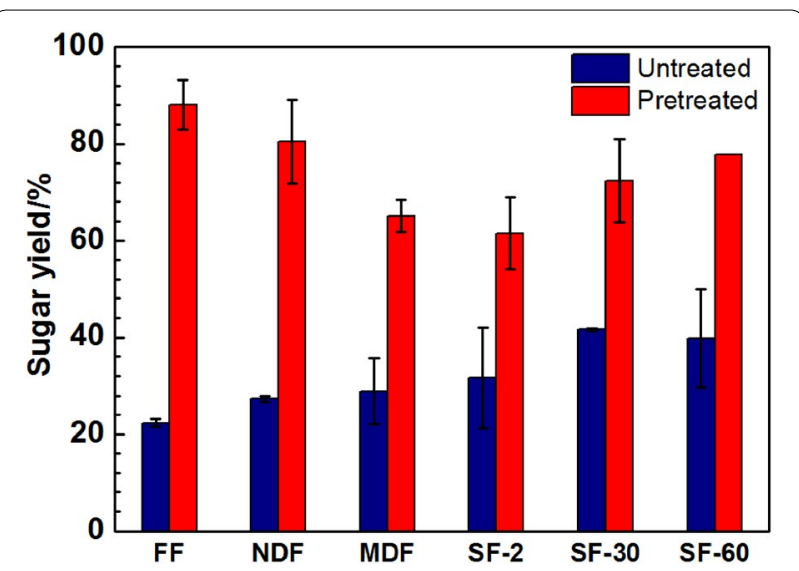

Fig. 3 Sugar yields of untreated and pretreated feedstock 
results indicate that higher moisture content is helpful to improve further enzymatic hydrolysis after ICSE pretreatment (Figs. 1i and 3); Sui and Chen drew the same conclusion by using normal steam explosion pretreatment on corn stover (Sui and Chen 2015). However, this impact was less obvious on the samples which were soaked for short durations, i.e., $2 \mathrm{~h}$. In addition, whether it is treated or not, the sugar yield of SF-30 was close to SF-60. So, $30 \mathrm{~h}$ is enough to improve the degradability of lignocellulose. Though the moisture content of NDF and SF-2 was similar (about 63\%), their sugar yields were quite different due to the hornification effect. Soaking process enabled lignocellulose to absorb moisture, but the shrinkage of internal fibers could not be fully recovered. It also demonstrated that the moisture content was not the only factor to predominate the enzymatic hydrolysis, but structure of feedstocks might be more pivotal on accessibility of cellulase than expected (Fernandes et al. 2004).

\section{The morphological and micro-structural analysis on feedstock}

So far, compared with MDF, ICSE pretreatment had more efficient impacts on FF and SF. The macroscopic appearance of feedstocks under different conditions is shown in Fig. 4; both FF and SF-60 were full of water, which seem to be more resilient than dried feedstock. Similar with wood industry, the morphological structure of dried wood could get back in shape after absorbing some water (Wang et al. 2006). Feedstock was destructed by steam explosion which turned into more uniform and reduced the particle size. As an order of destruction, FF occupied first place followed by dried feedstocks. It was interesting to note that soaked feedstock produced non-uniform particles when subjected to ICSE and some of the biomass components were unable to be reached by hot steam. The similar findings were observed previously, because the hornification effects would lead to different biomass structures between FF and SF and potentially impact ICSE pretreatment (Fernandes et al. 2004). Soaking could not infiltrate to all parts due to mass transfer limitation at short time, which formed the un-soaked tissue mainly located in inner part of biomass (Borrega and Kärenlampi 2010).

The sample used for SEM micrographs was dried by freeze-drying that preserved cell structure (Fig. 4), whereas the NDF and MDF undergone a drying process at ambient and moderately high temperature, and their cell wall becomes very vulnerable due to dehydration. As shown in Fig. 4, the pores in FF were biggest among three feedstocks, which facilitate the steam or hot water penetrating biomass and enhancing explosion force to
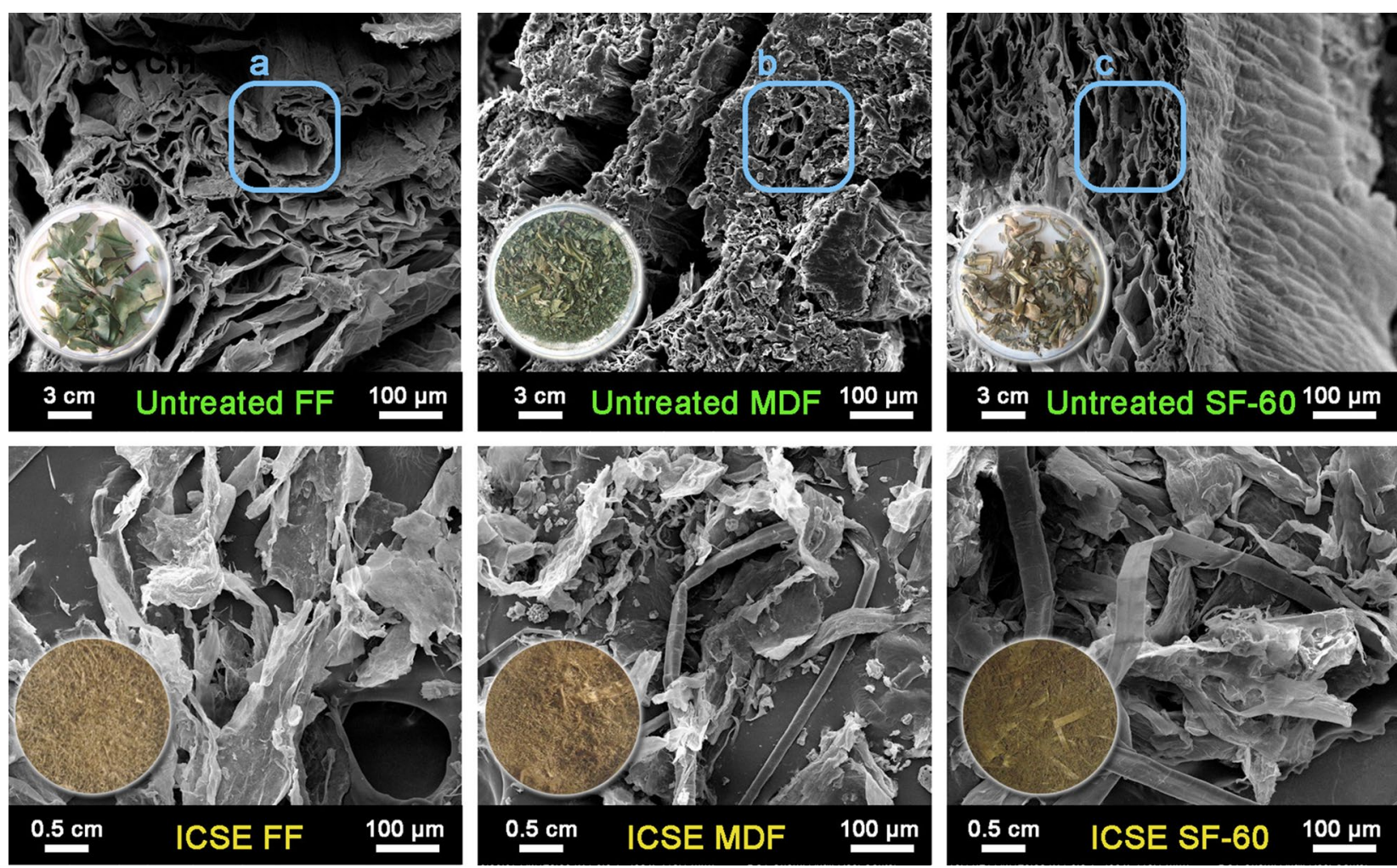

Fig. 4 Photographs (round in the left bottom) and SEM microscopic appearance of biomass. The feedstocks included untreated and ICSE-pretreated sweet potato vines for FF, MDF and SF-60 h. a-c mark the pores of lignocellulose 
degrade components. When the feedstock was totally dried, all pores in MDF shrank to about one twenty of area of pores in FF due the hornification effects (Fernandes et al. 2004). It blocked the entrance of steam and hot water into pores and lead to a lower accessibility of vapors. If the MDF was soaked in the water, the rehydrating feedstocks tend to return previous status with big pores. Nevertheless, the irreversible ruins on cell wall by drying process have occurred, which leads to the pores of SF much bigger than MDF's, but still smaller than FF's.

After ICSE pretreatment, all feedstocks were similar because of their similar moisture content (Table 1), but there was still obvious different observations by naked eyes. The particles of ICSE-pretreated FF were the smallest and distributed evenly. Inversely, the particles of ICSEpretreated MDF were not homogeneous and the particle size was bigger than ICSE-pretreated FF particles. Some big debris could be found in pretreated MDF and SF-60.

\section{The role of water and steam in ICSE pretreatment}

Given the basic principle of steam explosion, the mechanical force is generated by the expanding gas (water vapors). So, changes of gas volume during the working temperature range may be helpful to enhance the destruction impact of the steam explosion. For the vaporization from hot water generated huge volume steam subsequently causing biomass degradation.

Though the presence of higher moisture content seems attractive for steam explosion, however, the high moisture content of biomass would require more energy due to higher specific heat capacity of water. On the other hand, it would not possible for all liquid water to transform into steam during the explosion if the moisture content is high, even with heavier inputs of energy. Roughly calculation for the energy input and steam generation during steam explosion can be undertaken as Eq. 4, which showed the climbing amount of steam $\left(m_{\mathrm{s}}\right)$ with the increase of $C_{\mathrm{m}}$, where, $1 \mathrm{~kg}$ biomass with $C_{\mathrm{m}}$ moisture content was heated from 25 to $230{ }^{\circ} \mathrm{C}(1.8 \mathrm{MPa})$. Since the change of specific heat capacity is little within this temperature range, the average values of specific heat capacity for water and feedstock are 4.37 and $1.7 \mathrm{~kJ} /(\mathrm{kg} \mathrm{K})$, respectively. The vaporization heat of water at $230{ }^{\circ} \mathrm{C}$ is $1812.6 \mathrm{~kJ} / \mathrm{kg}$. When the $C_{\mathrm{m}}$ is lower than $27.50 \%$, theoretically, the biomass should become completely dry subjected to ICSE. But what happened, the condensed water from heating steam increased the moisture content of pretreated biomass. Therefore, the moisture content of wet feedstock helped to remove the hemicelluloses and other water-soluble components, and generated more inner steam for improved explosion impact (Sui and Chen 2015).

$$
m_{S}=\frac{1 \mathrm{~kg} \times(230-25) \mathrm{K} \times\left(1.7 \mathrm{~kJ} / \mathrm{kg} \cdot \mathrm{K} \times\left(1-C_{\mathrm{m}}\right)+4.37 \mathrm{~kJ} / \mathrm{kg} \cdot \mathrm{K} \times C_{\mathrm{m}}\right)}{1812.6 \mathrm{~kJ} / \mathrm{kg}} .
$$

convenient evaluation, if pressure changes are ignored, 1 $\mathrm{L}$ air at $25^{\circ} \mathrm{C}$ would be $1.7 \mathrm{~L}$ at $230{ }^{\circ} \mathrm{C}$ (Eq. 2). However, $1 \mathrm{~L}$ water at $25^{\circ} \mathrm{C}$ would be transformed to $2100 \mathrm{~L}$ steam at $230{ }^{\circ} \mathrm{C}$ (Eq. 3). Therefore, higher moisture content potentially produces more inner steam for mechanical work which subsequently can destroy the compact structure of biomass. But the steam which is out of feedstock only can convert their thermal energy to kinetic energy.

$$
\begin{gathered}
\text { Air volume }=\frac{T_{2} P_{1}}{T_{1} P_{2}} V 1=\frac{(230+273) \mathrm{K}}{(25+273) \mathrm{K}} \times 1 \mathrm{~L}=1.7 \mathrm{~L} \\
\text { Steam volume }=\frac{1000 \mathrm{~g}}{\frac{18 \mathrm{~g}}{\mathrm{~mol}}} \times 37.8 \frac{\mathrm{L}}{\mathrm{mol}}=2100 \mathrm{~L}
\end{gathered}
$$

In the small pores of biomass, the steam explosion process followed two steps. The first part is heating: the gas and liquid were heated from room temperature to setting temperature about $230{ }^{\circ} \mathrm{C}$. The water in the biomass remained as liquid phase because the working pressure was always higher than saturated vapor pressure. So, the liquid hot water dissolved partial lignocelluloses and other water-soluble components. The next step was flash depressurizing. When the pressure in working vessel is instantly released to atmosphere pressure,

\section{Effects of moisture content on lignocellulose pretreatment} Due to the high moisture content of lignocellulose, researchers had studied its effects on various pretreatment methods such as ionic liquid pretreatment, grinding, and steam explosion (Table 3). Grinding of wet lignocellulose would consume more energy and finally have a bigger particle size than dried feedstock (Barakat et al. 2015). Mixing water with ionic liquid would lead to a lower pretreatment efficiency, though it would reduce reagents and the whole pretreatment cost (Shi et al. 2014a).

Fortunately, the moisture content of lignocellulose would improve pretreated efficiency of steam explosion or supercritical $\mathrm{CO}_{2}$ pretreatment. Compared with dried feedstock, wet lignocellulose would prohibit the pyrolysis of hemicelluloses and facilitates the following enzymatic hydrolysis during steam explosion pretreatment (Sui and Chen 2015). In addition, previous works about some special steam explosion, such as the pre-soaking lignocellulosic biomass with $\mathrm{SO}_{2}$ before the pretreatment (Cullis et al. 2004) and the addition of ammonia in the steam water (Moniruzzaman et al. 1997), showed higher sugar yield than ones obtained from dried feedstock and in agreement with this study. Considering the high cost of lignocellulosic pretreatment, the steam 
explosion is a better option. It has an appealing trait, which does not require too much refining operation before pretreatment and allows simplifying the handling on raw feedstock.

Though researchers studied moisture effects on pretreatment efficiency, few of them studied impacts of intracellular moisture. Here, FF showed $88.05 \%$ sugar yield after ICSE pretreatment which was competitive when compared to other resources and steam explosion pretreatment. Conclusively, the sweet potato vines and ICSE would be an excellent resource and pretreatment process for the preparation of high-value substrates for microbial fermentation.

\section{The strategies for feedstock collection and transportation}

The collection, storage, transportation, and pretreatment of biomass are energy consuming processes. The moisture content has significant impacts on these processes (Kudakasseril et al. 2013). In US, cellulosic ethanol plant uses common feedstock like agriculture residue, which are naturally dried for 1-2 months in the fields and bunched by rotary baler. The dry feedstock could save the cost of transportation (Axelsson et al. 2012). However, this path is not suitable for cellulosic plants in China, because the agricultural residues cannot be allowed to stay too long in the field due to the following farming, and the wet feedstock with high moisture content is heavy enough to cost high transportation charges (Shi et al. 2014b).

The research has demonstrated that the fresh and soaked biomass (pre-dried) performed better after ICSE pretreatment than dried feedstock, considering the dramatical improvement of carbohydrate content and sugar yield, and the lower production of inhibitors. Therefore, two strategies based on ICSE pretreatment were proposed (Fig. 5) for agricultural countries which are forced to use high-density cultivation such as China and Pakistan to fulfill the requirements of their huge populations.

The first strategy follows the ordinary handling process before pretreatment, but the dry biomass needs to be soaked to regain the moisture content and to wash out the monosaccharides. The high moisture content will benefit the ICSE performance with the improvement of sugar yield. Attractively the soaked water can also be recycled for next soaking, which concentrates the soluble sugar form raw biomass and avoid the accumulation of inhibitors during thermal pretreatment.

In the second proposed strategy, fresh biomass may be directly subjected to ICSE at an adjacent working station near the farm. The liquid phase of pretreated biomass can be either returned to field as fertilizer or utilized for biogas production, since it contains plentiful organic compounds. The second strategy is more suitable to the populous countries, including China, where crop rotation is required either due to seasonal issues or due to heavy requirements of food and feed. For example, in eastern China, the crop residue should be moved quickly within 1 month for the following cultivation; thus, there is no time available for field drying (Rasmussen et al. 1980). Moreover, ICSE can efficiently decrease particle size by destroying the compact structure and elevate the sugar content, when fresh biomass is used. Moreover,

Table 3 Summary for the effects of moisture content on lignocellulose pretreatment

\begin{tabular}{|c|c|c|c|c|c|}
\hline Pretreatment & Biomass & Sugar yield & Advantage & Disadvantage & Refs. \\
\hline Ionic liquid & Switchgrass & $70 \%$ & $\begin{array}{l}\text { Decrease the cost of ionic liquid } \\
\text { pretreatment }\end{array}$ & $\begin{array}{l}\text { The existence of water will } \\
\text { hamper the efficiency of } \\
\text { pretreatment }\end{array}$ & Shi et al. (2014a) \\
\hline Grinding & $\begin{array}{l}\text { Wheat straw, } \\
\text { corn stover etc. }\end{array}$ & NA & NA & $\begin{array}{l}\text { Result in additional energy } \\
\text { requirement and higher } \\
\text { final particle size }\end{array}$ & Barakat et al. (2015) \\
\hline Supercritical $\mathrm{CO}_{2}$ & $\begin{array}{l}\text { Southern yellow } \\
\text { pine }\end{array}$ & $84.7 \%$ & $\begin{array}{l}\text { The increase of initial moisture } \\
\text { content will obtain higher final } \\
\text { sugar yield }\end{array}$ & NA & Kim and Hong (2001) \\
\hline Steam explosion & Corn stover & $90 \%$ & Improve the sugar yield & $\begin{array}{l}\text { Not benefit for the quickly } \\
\text { heating of biomass during } \\
\text { pretreatment }\end{array}$ & Sui and Chen (2015) \\
\hline $\begin{array}{l}\text { Ammonia fiber } \\
\text { steam explosion }\end{array}$ & Corn stalk & $80 \%$ & $\begin{array}{l}\text { Increase of moisture content } \\
\text { does not hamper the enzymatic } \\
\text { hydrolysis of lignocellulose }\end{array}$ & Ditto & $\begin{array}{l}\text { Moniruzzaman et al. } \\
\text { (1997) }\end{array}$ \\
\hline Steam explosion & Softwood & $60-90 \%$ & $\begin{array}{l}\text { Prompt the enzymatic hydrolysis } \\
\text { and reduce the hydrolysis of } \\
\text { hemicelluloses content }\end{array}$ & Ditto & Cullis et al. (2004) \\
\hline Acid steam explosion & Corn stover & $\begin{array}{l}>90 \% \\
\text { (Xylose) }\end{array}$ & High soluble sugar yield & Ditto & Emmel et al. (2003) \\
\hline
\end{tabular}




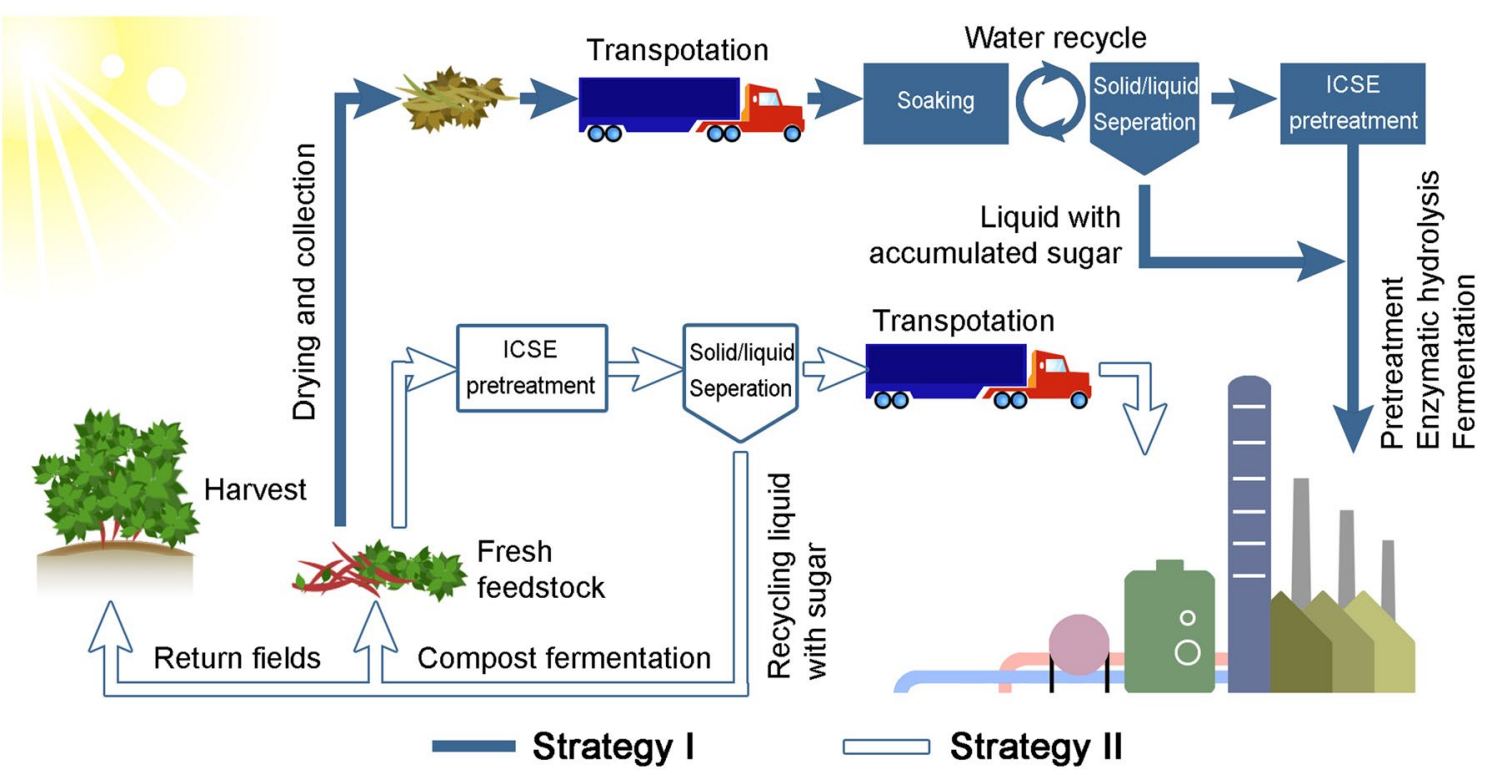

Fig. 5 Strategies for collection and pretreatment of biomass before factory production based on ICSE

transportation of the onsite ICSE-pretreated solid to the biofuel producing plant can also save the time and cost, comparing with onsite drying or transporting fresh biomass (Fig. 5).

\section{Conclusion}

The present study focused on developing a low-cost strategy for the pretreatment of feedstock to biofuel-producing industry. The moisture content of lignocellulosic biomass can be utilized to enhance the enzymatic hydrolysis via ICSE, instead of drying. Moreover, ICSE pretreatment raises the carbohydrate content up to 1.43 -folds with concomitant lowering of the inhibitors in the hydrolysate. The sugar yield of ICSE-pretreated fresh feedstock was improved by 2.5 -folds and reached to $88.05 \%$, which was like soaking the biomass for $60 \mathrm{~h}$, suggesting that the use of fresh biomass would be the best way to run ICSE.

\section{Abbreviations}

ICSE: instant catapult steams explosion; FF: fresh feedstock; NDF: naturally dried feedstock; MDF: manually dried feedstock in oven; SF-2: soaking feedstock for 2 h; SF-30: soaking feedstock for 30 h; SF-60: soaking feedstock for $60 \mathrm{~h}$; SEM: scanning electron microscopy; TGA: thermal gravimetric analysis; DTG: differential thermal gravimetric analysis; 5-HMF: 5-hydroxymethyl furfural.

\section{Authors' contributions}

LL carried out this experiment, data collection, data analysis, and manuscript preparation. CL conducted the research, investigation process, artwork, and manuscript preparation. JQ and KL made equal contribution to prepare initial manuscript. MAM revised the manuscript to its final form. All authors read and approved the final manuscript.

\section{Author details}

1 State Key Laboratory of Microbial Metabolism, School of Life Sciences and Biotechnology, Shanghai Jiao Tong University, Shanghai 200240, China.
${ }^{2}$ Department of Wood Science, University of British Columbia, Vancouver V6T 1Z4, Canada. ${ }^{3}$ School of Life Science and Biotechnology, Dalian University of Technology, Dalian, Liaoning 116023, China. ${ }^{4}$ Department of Bioinformatics and Biotechnology, Government College University Faisalabad, Faisalabad 38000, Pakistan.

\section{Acknowledgements}

We appreciate the kind support of Prof. Feng-Wu Bai. We also would like to thank Xue-Mi Hao, Bo-Yu Geng, and Bo-Wen Jin for technical assistance and valuable discussion.

\section{Competing interests}

The authors declare that they have no competing interests.

Availability of data and materials

All data are presented in this main manuscript.

Consent for publication

Not applicable.

Ethics approval and consent to participate

Not applicable.

\section{Funding}

This work was supported by the National Natural Science Foundation of China [Grant Numbers 51561145014, 21536006, 21406030].

\section{Publisher's Note}

Springer Nature remains neutral with regard to jurisdictional claims in published maps and institutional affiliations.

Received: 7 September 2017 Accepted: 14 November 2017 Published online: 27 November 2017

\section{References}

Agbor VB, Cicek N, Sparling R et al (2011) Biomass pretreatment: fundamentals toward application. Biotechnol Adv 29:675-685. https://doi.org/10.1016/j. biotechadv.2011.05.005 
Axelsson L, Franzén M, Ostwald M et al (2012) Perspective: jatropha cultivation in southern India: Assessing farmers' experiences. Biofuels Bioprod Biorefining 6:246-256. https://doi.org/10.1002/bbb

Barakat A, Monlau F, Solhy A, Carrere H (2015) Mechanical dissociation and fragmentation of lignocellulosic biomass: effect of initial moisture, biochemical and structural proprieties on energy requirement. Appl Energy 142:240-246. https://doi.org/10.1016/j.apenergy.2014.12.076

Borrega M, Kärenlampi PP (2010) Hygroscopicity of heat-treated Norway spruce (Picea abies) wood. Eur J Wood Wood Prod 68:233-235. https:// doi.org/10.1007/s00107-009-0371-8

Carrier M, Loppinet-Serani A, Denux D et al (2011) Thermogravimetric analysis as a new method to determine the lignocellulosic composition of biomass. Biomass Bioenergy 35:298-307. https://doi.org/10.1016/j. biombioe.2010.08.067

Cullis IF, Saddler JN, Mansfield SD (2004) Effect of initial moisture content and chip size on the bioconversion efficiency of softwood Lignocellulosics. Biotechnol Bioeng 85:413-421. https://doi.org/10.1002/bit.10905

Dhakal HN, Zhang ZY, Richardson MOW (2007) Effect of water absorption on the mechanical properties of hemp fibre reinforced unsaturated polyester composites. Compos Sci Technol 67:1674-1683. https://doi. org/10.1016/j.compscitech.2006.06.019

Emmel A, Mathias AL, Wypych F, Ramos LP (2003) Fractionation of Eucalyptus grandis chips by dilute acid-catalysed steam explosion. Bioresour Technol 86:105-115. https://doi.org/10.1016/S0960-8524(02)00165-7

Fao U (2016) FAOSTAT_data_7-19-2017-3. In: Food Agric Organ United Nations. http://www.fao.org/faostat/en/\#data/QC

Fernandes DJ, Gil MH, Castro JAAM (2004) Hornification—its origin and interpretation in wood pulps. Wood Sci Technol 37:489-494. https://doi. org/10.1007/s00226-003-0216-2

Frederick N, Zhang N, Ge X et al (2014) Poplar (Populus deltoides L.): the effect of washing pretreated biomass on enzymatic hydrolysis and fermentation to ethanol. ACS Sustain Chem Eng 2:1835-1842. https://doi. org/10.1021/sc500188s

Galbe M, Zacchi G (2012) Pretreatment: the key to efficient utilization of lignocellulosic materials. Biomass Bioenergy 46:70-78. https://doi. org/10.1016/j.biombioe.2012.03.026

Gong L, Huang L, Zhang Y (2012) Effect of steam explosion treatment on barley bran phenolic compounds and antioxidant capacity. J Agric Food Chem 60:7177-7184. https://doi.org/10.1021/jf301599a

Jibril H, Perez-Maldonado RA, Mannion PF, Farrell DJ (1999) The nutritive value of sweet potato vines for broilers. In: Australian poultry science symposium, pp 158-161

Jönsson LJ, Alriksson B, Nilvebrant N-O (2013) Bioconversion of lignocellulose: inhibitors and detoxification. Biotechnol Biofuels 6:16. https://doi. org/10.1186/1754-6834-6-16

Kim KH, Hong J (2001) Supercritical CO2 pretreatment of lignocellulose enhances enzymatic cellulose hydrolysis. Bioresour Technol 77:139-144. https://doi.org/10.1016/S0960-8524(00)00147-4

Kudakasseril KJ, Raveendran NG, Hussain A, Vijaya GS (2013) Feedstocks, logistics and pre-treatment processes for sustainable lignocellulosic biorefineries: a comprehensive review. Renew Sustain Energy Rev 25:205-219. https://doi.org/10.1016/j.rser.2013.04.019

Liu CG, Liu LY, Zi LH et al (2014a) Assessment and regression analysis on instant catapult steam explosion pretreatment of corn stover. Bioresour Technol 166:368-372. https://doi.org/10.1016/j.biortech.2014.05.069

Liu LY, Hao XM, Liu CG, Bai FW (2014b) Evaluation of instant catapult steam explosion combined with chemical pretreatments on corn stalk by components and enzymatic hydrolysis analysis. Huagong Xuebao 65:4557-4563

Moniruzzaman M, Dale BE, Hespell RB, Bothast RJ (1997) Enzymatic hydrolysis of high-moisture corn fiber pretreated by AFEX and recovery and recycling of the enzyme complex. Appl Biochem Biotechnol 67(1):113-126

Mosier N, Wyman C, Dale B et al (2005) Features of promising technologies for pretreatment of lignocellulosic biomass. Bioresour Technol 96:673-686. https://doi.org/10.1016/j.biortech.2004.06.025

Qu C, Li B, Wu H, Giesy JP (2012) Controlling air pollution from straw burning in china calls for efficient recycling. Environ Sci Technol 46:7934-7936. https://doi.org/10.1021/es302666s

Rasmussen PE, Allmaras RR, Rohde CR, Roager NC (1980) Crop residue influences on soil carbon and nitrogen in a wheat-fallow system. Soil Sci Soc Am J 44:596-600
Rocha GJM, Gonçalves AR, Oliveira BR et al (2012) Steam explosion pretreatment reproduction and alkaline delignification reactions performed on a pilot scale with sugarcane bagasse for bioethanol production. Ind Crops Prod 35:274-279. https://doi.org/10.1016/j.indcrop.2011.07.010

Sanchez-Silva L, López-González D, Villaseñor J et al (2012) Thermogravimetricmass spectrometric analysis of lignocellulosic and marine biomass pyrolysis. Bioresour Technol 109:163-172. https://doi.org/10.1016/j. biortech.2012.01.001

Shi J, Balamurugan K, Parthasarathi R et al (2014a) Understanding the role of water during ionic liquid pretreatment of lignocellulose: co-solvent or anti-solvent? Green Chem 16:3830-3840. https://doi.org/10.1039/ c4gc00373j

Shi T, Liu Y, Zhang L et al (2014b) Burning in agricultural landscapes: an emerging natural and human issue in China. Landsc Ecol 29:1785-1798

Sluiter A, Hames B, Ruiz R et al (2012) Determination of structural carbohydrates and lignin in biomass. Lab Anal Proced 1617:1-16

Sui W, Chen H (2015) Water transfer in steam explosion process of corn stalk. Ind Crops Prod 76:977-986. https://doi.org/10.1016/j.indcrop.2015.08.001

Tan T, Yu J, Lu J, Zhang T (2010) Biofuels in China. Springer, Berlin

Tian Y, Zhao L, Meng H et al (2009) Estimation of un-used land potential for biofuels development in China. Appl Energy 86:S77-S85. https://doi. org/10.1016/j.apenergy.2009.06.007

Vander PEC, Bakker RR, Baets P, Eggink G (2014) By-products resulting from lignocellulose pretreatment and their inhibitory effect on fermentations for (bio)chemicals and fuels. Appl Microbiol Biotechnol 98:9579-9593. https://doi.org/10.1007/s00253-014-6158-9

Vidal BC, Dien BS, Ting KC, Singh V (2011) Influence of feedstock particle size on lignocellulose conversion - a review. Appl Biochem Biotechnol 164:1405-1421. https://doi.org/10.1007/s12010-011-9221-3

Wang W, Sain M, Cooper PA (2006) Study of moisture absorption in natural fiber plastic composites. Compos Sci Technol 66:379-386. https://doi. org/10.1016/j.compscitech.2005.07.027

Xia L, Wei W, Jiang Y, et al (2013) Comparative analysis of chemical composition of sweet potato vines from different cultivars. 34:238-240. https:// doi.org/10.7506/spkx1002-6630-201310052

Zhan J, Lin H, Shen Q et al (2013) Potential utilization of waste sweetpotato vines hydrolysate as a new source for single cell oils production by Trichosporon fermentans. Bioresour Technol 135:622-629. https://doi. org/10.1016/j.biortech.2012.08.068

\section{Submit your manuscript to a SpringerOpen ${ }^{\circ}$ journal and benefit from:}

- Convenient online submission

- Rigorous peer review

- Open access: articles freely available online

- High visibility within the field

- Retaining the copyright to your article

Submit your next manuscript at $\gg$ springeropen.com 